\title{
A ESCOLARIZAÇÃO DO ESTUDANTE COM DEFICIÊNCIA EM TEMPOS DE PANDEMIA DA COVID-19: TECENDO ALGUMAS POSSIBILIDADES
}

\author{
Tamara França de Almeida Magalhães ${ }^{\mathrm{i}}$
}

\begin{abstract}
Resumo: A pandemia da Covid-19 tem impactado os sistemas de ensino no mundo inteiro. Medidas de isolamento social obrigaram o fechamento de escolas e universidades, sendo implementada a educação a distância ou ensino remoto emergencial. Nesta direção este artigo tem como objetivo tecer reflexões sobre a escolarização do estudante com deficiência e os impactos desta modalidade de ensino no AEE. Como metodologia de pesquisa utilizamos a pesquisa bibliográfica e documental, buscando referências que em diálogo com a abordagem do modelo social da deficiência, nos oportunizasse caminhos para desenvolvermos a reflexão proposta. Ressaltamos, que não serão apresentados necessariamente elementos conclusivos, mas temas que colaboram com este debate de grande relevância na atualidade.
\end{abstract}

Palavras-chave: Pandemia da covid-19; Ensino remoto emergencial; Atendimento educacional especializado.

\section{THE SCHOOLING OF STUDENT WITH DISABILITIES IN PANDEMIC TIMES OF COVID-19: WEAVING SOME POSSIBILITIES.}

\begin{abstract}
The Covid-19 pandemic has impacted education systems worldwide. Measures of social isolation forced the closure of schools and universities, with distance education or emergency remote education being implemented. In this direction, this article aims to reflect on the schooling of students with disabilities and the impacts of this teaching modality in AEE. As a research methodology we use bibliographic and documentary research, looking for references that, in dialogue with the approach of the social model of disability, would provide us with ways to develop the proposed reflection. We emphasize that conclusive elements will not necessarily be presented, but themes that collaborate with this debate of great relevance today.
\end{abstract}

Key words: Covid-19 pandemic; Emergency remote education; Specialized educational assistance.

\section{Introdução}

"Movo-me como educador, porque, primeiro, me movo como gente" Paulo Freire

As transformações sociais que ocorrem no mundo em razão da pandemia da Covid-19 desde o início de 2020, têm ocasionado mudanças em diversas áreas da sociedade de proporções ainda impossíveis de serem mensuradas. A necessidade da imposição de práticas de distanciamento social para o controle e redução do contágio da doença, impactaram 
drasticamente setores basilares da estrutura do capitalismo como a economia, a saúde e a educação. Nota-se, como bem destacou Diniz (2020), que o Brasil e o mundo passam por uma crise civilizatória de dimensões inimagináveis.

"O ineditismo deste evento não nos permite tecer considerações a curto ou médio prazo sobre como será o mundo e as múltiplas relações que a humanidade construiu. Não se trata de considerar o elemento do isolamento social como implicador do modo de ver o mundo futuramente. $\mathrm{O}$ isolamento social promoveu transformações econômicas severas imediatas, com a parada obrigatória de inúmeros setores, modificou a nossa relação com a arte, devido à ausência do compartilhamento presencial de experiências de fruição e, no caso da educação, promove desconstruções sob a forma de como o ensino e a aprendizagem são vistos socialmente" (ARRUDA, 2020, p. 258).

No âmbito destas mudanças, as instituições escolares, bruscamente afetadas pelas imposições da crise sanitária, tiveram que adaptar a sua rotina, bem como as suas práticas educativas a esta nova realidade. Neste cenário, a educação em tempos de pandemia da Covid-19, passa a entender a tecnologia como um espaço de lutas, transformações, mas também de desigualdades (BARRETO E ROCHA, 2020). Ademais, não podemos deixar de destacar que em razão da crise sanitária, o direito à educação tem sido abruptamente privado para muitos estudantes nos diversos níveis de ensino.

Nesta direção, corroborando com Morel (2020), compreendemos que a suspensão das atividades escolares está entre as medidas que mais impactou a vida das pessoas, tanto no que diz respeito ao controle da propagação do vírus, quanto nas dinâmicas de reprodução social. A suspensão das aulas presenciais substituídas pelo ensino remoto emergencial (ERE) impôs uma mudança radical de como a vida é conduzida pois o simples funcionamento dos sistemas de ensino, sobretudo na educação básica, impacta fortemente a rotina de milhões de estudantes, principalmente daqueles que apresentam alguma necessidade educacional específica como é o caso o estudante com deficiência.

Diante disso, o objetivo deste artigo é tecer algumas reflexões sobre a escolarização do estudante com deficiência no contexto da pandemia da Covid-19, bem como sobre os impactos do ERE no atendimento educacional especializado (AEE). Para desenvolvimento de nosso estudo, como metodologia utilizamos a abordagem da pesquisa bibliográfica e documental, por meio da revisão de literatura. Cabe mencionar, que as análises serão encaminhadas em diálogo com os pressupostos da abordagem teórica do modelo social da deficiência, pois assim como Piccolo e Mendes (2013) compreendemos a deficiência como produto da opressão social inserida por e sobre as diferenças expressas pelo corpo dos sujeitos 
não levando em consideração a diversidade e a multiplicidade de necessidades, como explicitado no contexto da pandemia da Covid-19 (UNESCO, 2020).

Ressaltamos, que nosso objetivo não é apresentar necessariamente elementos conclusivos para as reflexões aqui propostas, mas nesta perspectiva colaborar com o debate, contribuindo para uma melhor compreensão de uma temática que adquire ainda mais relevância na atualidade.

\section{Uma nova sociedade na pandemia da Covid-19: sobre a crise sanitária no Brasil e no Mundo}

O surgimento do novo coronavírus (SARS-COV-2) em Wuhan na China que originou a doença denominada Covid-19, já pode ser considerado um marco importante na história contemporânea. Surgida em dezembro de 2019 e declarada como pandemia pela Organização Mundial da Saúde (OMS) em 11 de março de 2020, tem sido considerada uma doença grave que pode levar a síndrome respiratória aguda, hospitalização e morte.

Segundo a OMS, até 22 de junho de 2020 foram confirmados no mundo 8.860.331 casos de Covid-19 e 465.740 mortes. Os dados da Universidade Johns Hopkins apontam ainda a marca de 9 milhões de infectados no mês de junho sendo Estados Unidos, Brasil, Reino Unido, Itália e França os países mais afetados pela pandemia no mundo.

O Brasil, atualmente o epicentro da Covid- 19 na América Latina, teve o seu primeiro caso confirmado em 26 de fevereiro de 2020. Desde então os dados vem aumentando progressivamente indicando o avanço da doença em várias regiões do país. Em 22 de junho de 2020 o Ministério da Saúde apresentou os seguintes indicadores para os casos de Covid-19 no Brasil: 1.106.470 casos confirmados e 51.271 mortes. Os estados mais afetados encontram-se nas regiões sudeste, nordeste e norte sendo São Paulo e Rio de Janeiro, respectivamente, os estados mais afetados pela doença.

É válido ressaltar que em razão das subnotificações, os índices de contaminados podem ser ainda maiores, uma vez que o país não tem realizado testes de Covid-19 em massa na população, conforme orientação da OMS. Couto; Couto e Cruz (2020) ressaltam que infectologistas acreditam que os números oficiais podem ser apenas $10 \%$ do total, indicando uma subnotificação dos casos e maior gravidade da pandemia.

Com o avanço da Covid-19 no mundo e a alta taxa de letalidade provocada por ela, a OMS indicou o isolamento social como a mais eficiente estratégia para enfrentamento do vírus e diminuição do contágio. Políticas sanitárias duras e de caráter socialmente coercitivo 
precisaram ser imediatamente implementadas e desde então, fronteiras entre países foram fechadas, assim como atividades comerciais, espaços de lazer, escolas e universidades suspensas.

Aqui no Brasil, desde a segunda quinzena do mês de março quando foram iniciadas as primeiras medidas de isolamento social, vivemos especialmente as imposições de uma situação que independente do grau de envolvimento e comprometimento do executivo federal, mudou de forma drástica o cotidiano da população (FILHO; ANTUNES; COUTO; 2020).

Além disso, o país tem apresentado dificuldades para enfrentamento da pandemia, devido a uma política de afrouxamento do isolamento social em detrimento da conservação da economia (BARRETO; ROCHA, 2020). Neste cenário, o crescimento de um discurso obscurantista, que nega tanto a gravidade da doença quanto a importância dos cuidados para combatê-la, ganha destaque nos discursos de autoridades do país. Conforme destacam Couto; Couto; Cruz (2020), o Brasil foi o único país que no auge da pandemia trocou de ministros da saúde porque o presidente queria alguém comprometido com o fim do isolamento social.

É fato que as medidas de isolamento têm promovido transformações sociais severas não só no Brasil, mas em todos os países acometidos pela pandemia. A suspensão obrigatória de inúmeros setores da sociedade impactou fortemente a economia, assim como a interrupção imediata das atividades escolares. A substituição das aulas presenciais por aulas em meios digitais, por exemplo, transformou abruptamente as relações pedagógicas, escancarando ainda mais as fragilidades dos sistemas de ensino em todo o mundo.

No contexto da pandemia, o retorno à normalidade não apresenta soluções fáceis. $\mathrm{O}$ mundo assiste uma nova forma de comportamento social em que os modos de se relacionar, de consumir e trabalhar foram severamente afetados. A crise sanitária, política e econômica potencializa ainda mais as desigualdades sociais já existentes. "Vivemos entre contradições políticas e econômicas, em meio a uma conjuntura globalizada adversa, agressiva e imensamente excludente" (COUTO, COUTO; CRUZ, 2020, P. 210).

Nesta perspectiva, como pensar a educação em um contexto de pandemia, quando, especificamente no caso brasileiro, muitas pessoas não têm acesso a itens básicos de higienização como sabão e água? Como garantir o acesso universal à educação através do ensino remoto quando muitos de nossos alunos não têm disponíveis internet e objetos tecnológicos? Como compreender os processos educativos em meio a uma população que subitamente perdeu sua renda, suas condições de moradia e alimentação? Como pensar a democratização da educação em um contexto ainda mais perverso para maioria dos estudantes brasileiros? 
Muitas questões se colocam neste momento, e repensar os processos educativos que mesmo anteriormente a pandemia, já se encontravam imersos em questões oriundas das desigualdades sociais, parece um desafio constante. Como compreender em meio a esta lógica, a escolarização de estudantes que, no escopo dos pressupostos meritocráticos, já se encontravam no último degrau da igualdade, uma vez que suas condições, sejam econômicas, físicas ou sociais já definiam suas possibilidades nesta engrenagem?

A problemática que se coloca para pensarmos a educação neste momento, estão intrinsecamente relacionadas a questões relativas a desigualdade social e a democratização do ensino. Compreender este momento significa colocar em xeque demandas que assolam o campo da educação há décadas. Temos, mais uma vez, a oportunidade de ressignificar todo este processo que sempre foi marcado por profundas desigualdades e interesses explicitados para além do verdadeiro sentido da educação que é a democratização.

\section{A educação na pandemia da Covid-19: sobre as desigualdades}

Em conformidade com a Organização das Nações Unidas (ONU) para educação, ciência e cultura (UNESCO, 2020), mais de 150 países implementaram o fechamento dos espaços escolares, provocando um grande impacto na população estudantil do mundo. Aproximadamente $80 \%$ destes estudantes estão fora da escola em razão da pandemia da Covid-19. Diante deste desafio, instituições de ensino em vários países movimentam suas estruturas buscando garantir a educação, agora a distância, a todos aqueles que estão impedidos de estar nos espaços escolares neste momento.

No Brasil, os estados e o governo federal implementaram alguns dispositivos legais a fim de orientar as ações dos sistemas educacionais em meio a crise sanitária. Sobre este aspecto Arruda (2020) destaca que o Brasil apresenta propostas difusas o que reflete a falta de liderança do Ministério da Educação (MEC). Foi emitida a portaria $n^{\circ} 343 / 2020$ que dispõe sobre a substituição das aulas presenciais por aulas em meios digitais e a medida provisória $\mathrm{n}^{\circ}$ 934 que propõe, dentre outras questões, a flexibilização da obrigatoriedade de 200 dias letivos de efetivo trabalho escolar.

O que temos observado é que a educação a distância e/ou ensino remoto que momentaneamente assume as responsabilidades do ensino presencial, tem impactado as relações pedagógicas no mundo inteiro. "Muitos países têm discutido mecanismos para que se garanta o convívio escolar e as conexões escolares, apesar da distância, buscando possibilitar 
uma política pública de manutenção das portas escolares abertas ainda que de forma virtual (ARRUDA, 2020, p. 263).

Contudo, o Relatório de Monitoramento Global da Educação (UNESCO 202), alerta para o fato de que, mesmo no contexto da pandemia, as oportunidades educacionais continuam sendo distribuídas de forma bastante desigual. Destaca ainda, que a crise atual irá perpetuar ainda mais as diferentes formas de exclusão, com mais de $90 \%$ da população estudantil mundial afetada pelo fechamento das escolas. $\mathrm{O}$ mundo está prestes a sofrer uma perturbação de grandes dimensões e sem precedentes na história da educação (UNESCO, 2020).

De acordo com Arruda (2020), países como França, Espanha, Portugal e Inglaterra que adotaram vínculo escolar por meio da mediação de tecnologias digitais de informação e comunicação (TDIC), relataram dificuldades quanto a gestão e implementação da aprendizagem remota. Dificuldades de alunos e professores para acompanharem as aulas e a falta de acesso de parcela da população às TDIC também foram apontados como situações que tornaram ainda mais complexo este processo.

Já a China, conforme os apontamentos do mesmo autor, ainda que promovendo uma rede de investimento maciço com empresas de tecnologia de grande porte, também apresentou impedimentos quanto a implementação do ensino a distância. Por lá, foram relatadas como complexas situações para a viabilização do acesso contínuo aos conteúdos elaborados, manter os alunos atentos e concentrados nos ambientes virtuais e dificuldades dos docentes em propiciar um ambiente mais interativo e desafiador.

Somam-se a estas situações, a pobreza e desigualdades extremas que interferirão diretamente nos resultados educacionais dos países que se enquadram nestas condições. Segundo Relatório da Unesco (2020), cerca de 40\% dos países de renda baixa e média-baixa não encaminharam nenhuma medida para apoiar os estudantes em risco de exclusão durante a crise da Covid-19. O relatório aponta ainda que a desigualdade de renda está aumentando em diversas partes do mundo, impedido milhões de estudantes de se beneficiarem da educação, principalmente por questões relacionadas a pobreza como miséria e desnutrição. E alertam: pobreza e desigualdade afetam a frequência escolar, a conclusão dos estudos as oportunidades de aprendizagem.

No Brasil, a emergência da pandemia acentuou o sofrimento vivido por populações pobres ou rapidamente empobrecidas. Em todas as regiões e cidades do país, o drama da fome se espalhou. Ademais, "o despreparo e a falta de comando no âmbito político, resultou na agudização da crise, não conseguindo o governo desenvolver um plano econômico de 
distribuição de renda, indispensável para a subsistência das pessoas nesta fase" (BERNARDES; ARRUZO; MONTEIRO; 2020, p. 191).

Tal fato torna explícito o que a síntese dos indicadores sociais (SIS-IBGE-2019) já apresentava antes da pandemia, que a situação de extrema pobreza no Brasil atinge cerca de 13,5 milhões de pessoas que sobrevivem com uma renda menor que R $\$ 145,00$ por mês. Isso significa um quarto da população brasileira vivendo abaixo da linha da pobreza. No entanto, do outro lado da balança, segundo dados da Pesquisa Nacional por Amostra de Domicílio Contínua (PNAD Contínua IBGE, 2018), 1\% da população mais rica concentra uma renda 34 vezes maior que a metade da população mais pobre. Não é à toa que o Brasil ocupa a $6^{\mathrm{a}}$ posição no ranking da desigualdade social no panorama internacional, apesar de ser um dos maiores produtores de alimentos do mundo (BERNARDES; ARRUZO; MONTEIRO; 2020).

Lembramos, que essa disparidade entre classes sociais no Brasil é resultado de um processo histórico de uma sociedade constituída por privilégios e não por direitos. Neste momento em que a pandemia da Covid-19 tem escancarado ainda mais a feiura das desigualdades sociais pelo mundo, o discurso de que ela é democrática, parece não fazer sentido algum. As geografias desiguais escancaram as entranhas do país e o divide entre os que têm e os que não têm sabão (BERNARDES; ARRUZO; MONTEIRO; 2020). Nesta lógica, são os estudantes mais carentes que passam pelas maiores dificuldades de acesso. Desde a falta de equipamentos tecnológicos e internet, até a própria alimentação. As diferenças sociais e digitais colocam os mais desfavorecidos em uma situação na qual correm o risco de ter perdas de aprendizagem ou abandonarem a escola (UNESCO, 2020).

Cabe mencionar, que as desigualdades sociais também são acompanhadas pela exclusão digital, uma vez que acesso à internet continua discrepante no país. Praticamente metade da população não tem acesso à internet ou tem acesso limitado, além de o uso da rede em muitas áreas urbanas e periféricas e zonas rurais, reforçarem as diferenças marcadas por vulnerabilidades sociais. A pesquisa TIC Domicílios apontou que enquanto $92 \%$ da classe média está conectada, apenas $48 \%$ da população de baixa renda classe D ou E, têm algum tipo de acesso à internet quase sempre via celular (TIC DOMICÍLIOS 2019).

Além disso, o amplo, mas não universal uso de celulares por jovens estudantes não significa acesso e disponibilidade permanente a rede de internet para a realização das atividades online. Filho (2020) aponta que recentemente, famílias relataram precisar apelar para parentes e vizinhos para que seus filhos pudessem ter acesso à internet e realizar o envio obrigatório de atividades, testes e materiais encaminhados pelas escolas. 
Diante deste complexo panorama da educação no país, outras questões emergem como a que nos trouxe ao desenvolvimento desta análise. Neste conturbado momento, possibilitar o acesso a educação para todos tem sido um desafio e para os estudantes com necessidades educacionais específicas um desafio ainda maior. As tecnologias que estão à disposição permitem o atendimento educacional especializado destes estudantes?

Assim como Barreto e Rocha (2020) compreendemos que a pandemia contemporânea expõe a necessidade de se desenvolver urgentemente, políticas públicas de igualdade educacional que pensem ações voltadas para a preservação da dignidade, identidade cultural, respeito à diferença e inclusão dos alunos que encontram-se nesse momento privados do direito a educação por inúmeros motivos. Nesta trajetória deve-se tomar todo o cuidado para que uma multidão de meninos e meninas não seja simplesmente esquecida e abandonada neste percurso (DINIZ, 2020).

\section{O processo de escolarização do estudante com deficiência em tempos de pandemia: tecendo algumas possibilidades}

A pandemia da Covid-19 impactou profundamente a vida escolar de estudantes no mundo inteiro. As aulas virtuais não têm atendido plenamente todos os alunos, evidenciando perturbadoras disparidades educacionais. As desigualdades sociais estão cada vez mais exacerbadas deixando milhões de crianças e jovens sem acesso a educação.

\footnotetext{
“As respostas à crise da COVID-19, que afetou 1,6 bilhão de estudantes, não deu atenção suficiente à inclusão de todos os estudantes. Enquanto $55 \%$ dos países de renda baixa optaram pelo ensino a distância online na educação primária e secundária, apenas $12 \%$ das famílias nos países menos desenvolvidos têm acesso à internet em casa. Mesmo abordagens com baixo uso de tecnologia não são capazes de assegurar a continuidade da aprendizagem. Entre os $20 \%$ mais pobres das famílias, apenas $7 \%$ possuem um rádio na Etiópia, e nenhuma possui um aparelho de televisão. No geral, cerca de $40 \%$ dos países de renda baixa e média-baixa não apoiam estudantes em situação de risco de exclusão. Na França, até $8 \%$ dos estudantes perderam contato com os professores após três semanas de confinamento" (UNESCO, 2020, p. 15).
}

O Relatório da Unesco (2020) alerta que muitos estudantes ainda encontram grandes barreiras para o acesso a uma educação de qualidade. Mesmo antes da pandemia, um em cada cinco adolescentes, jovens e crianças estava totalmente excluído da educação. Além disso, a existência de estigmas, estereótipos e discriminação significa que outros milhões são excluídos nas próprias salas de aula (UNESCO, 2020). 
Com a implementação das aulas virtuais, muitos estudantes se viram perdidos ou “esquecidos". Nesta dinâmica, questões relacionadas as desigualdades sociais como a falta de acesso a equipamentos de tecnologia, redes de internet, falta de alimentação e renda, evidenciam um contexto ainda mais grave para os estudantes que além de compartilharem de todas estas condições, apresentam necessidades específicas de aprendizagem como é o caso dos estudantes com deficiência.

Lembramos, que no Brasil, o Censo Escolar (2020) aponta que nos últimos anos, especificamente de 2014 a 2018, o número de matrículas de estudantes com deficiência nas instituições de ensino cresceu 33,2\%. Os dados evidenciam que neste mesmo período aumentou de $87,1 \%$ para $92,1 \%$ o número de alunos com deficiências incluídos em classes comuns, principalmente na rede pública de ensino. Possivelmente, uma outra crise de saúde aumentará ainda mais estes índices nos próximos anos, tendo em vista que o Ministério da Saúde notificou em 2019, 17.041 casos suspeitos de alterações no crescimento e desenvolvimento infantil relacionadas à infecção pelo vírus Zika e outras etiologias infecciosas. Destes, $3.332(19,6 \%)$ foram confirmados em virtude principalmente da existência da microcefalia ${ }^{\text {ii }}$.

Não podemos deixar de mencionar que o crescimento de matrículas de estudantes com deficiência nos sistemas de ensino é o resultado de uma crescente movimentação em prol da constituição de uma política, em que os direitos educacionais e sociais de pessoas com deficiências têm sido fortalecidos por meio dos princípios da educação inclusiva desde a década de 1990. Neste processo, a Lei de Diretrizes e Bases da Educação Nacional, de 1996, assim como a Política de Educação Especial na Perspectiva da Educação Inclusiva, de 2008, e mais recentemente o Estatuto da Pessoa com deficiência de 2015 garantem a inclusão e a oferta do Atendimento Educacional Especializado nos sistemas de ensino aos alunos com deficiência, transtorno global do desenvolvimento e altas habilidades ou superdotação.

Contudo, garantir o acesso à educação neste período tão adverso, não só as pessoas com deficiência, mas a todos os estudantes, tem sido desafiador. Em razão disso, buscando amenizar os impactos da pandemia nos sistemas educacionais, a Unesco (2020) organizou algumas recomendações para que as escolas consigam atender o maior número possível de alunos, dentre eles os estudantes com deficiência. Nas orientações, é sugerido que o poder público viabilize a implementação de medidas que garantam o acesso de estudantes de baixa renda ou com deficiências, como a instalação de computadores dos laboratórios da escola na casa dos alunos e ajuda com a ligação à internet. 
No Brasil, o Conselho Nacional de Educação (CNE) também emitiu parecer com diretrizes para orientar escolas da educação básica e instituições de ensino superior durante a pandemia. Com relação a Educação Especial, além de medidas de acessibilidade, que deverão ser definidas por estados e municípios observando os cuidados quanto a mediação, as atividades pedagógicas não presenciais deverão incluir os estudantes com deficiência, transtorno de espectro autista e altas habilidades/superdotação. Nesta direção, deverão ser consideradas as seguintes orientações:

Junto às atividades, deve ser assegurado o atendimento educacional especializado, que envolve parceria entre profissionais especializados e professores, para desempenhar suas funções na adequação de materiais, além de dar orientações e apoios necessários a pais e responsáveis. Como a atenção é redobrada para cada aluno, os profissionais do atendimento educacional especializado devem dar suporte às escolas na elaboração de planos de estudo individualizados, que levem em conta a situação de cada estudante. As famílias são, sempre, parte importante do processo (CNE, $2020, \mathrm{~s} / \mathrm{p})$.

Diante disso, surge a questão que tem tirado o sono de muitos professores, principalmente dos que realizam atendimento na educação especial: como pensar os encaminhamentos de um processo educativo que necessariamente baseia-se nas interações e mediações presenciais, quando não haverá mais, durante o isolamento social, o contato presencial do professor com o estudante capaz de propiciar um acompanhamento mais individualizado?

Como já mencionamos anteriormente, não é nossa intenção apresentar propostas conclusivas sobre esta questão, tampouco oferecer um manual de instruções de como fazer. Pretendemos neste momento buscar possibilidades que nos oriente, nós professores, a passar por este período de complexas transições em que avizinha-se um futuro onde modelo híbrido de educação pode tornar-se uma realidade.

Compreender a educação especial e os estudantes com deficiência no contexto da pandemia da Covid-19, onde também ficou explicitado que as ações governamentais não levam em consideração a diversidade e a multiplicidade de necessidades, torna-se urgente. Neste momento, em que muitos estudantes estão sofrendo perdas bruscas no desenvolvimento e aprendizagens, as pessoas com deficiência sofrem ainda mais pois, o simples fato de estar na escola possibilita ganhos extremamente importantes em vários aspectos de suas vidas.

Cabe mencionar, que para muitos destes estudantes, a escola é a única instituição que possibilita cuidados para além da questão pedagógica. A escola muitas vezes é a principal 
responsável pela alimentação bem como a "ponte" para outros atendimentos relacionados a saúde e assistência social. Ficar sem ela neste momento é uma perda irreparável para muitas crianças e jovens com deficiência, mais ainda quando consideramos as evidências científicas discutidas na literatura internacional e nacional que mostram a importância do convívio com a diversidade para a ampliação das possibilidades de desenvolvimento humano (SILVA ET AL, 2020).

Ademais, conforme a abordagem do Modelo Social- Os Disability Studies, a deficiência configura-se não como um problema trágico do campo médico, mas como uma situação de discriminação institucional e coletiva. Nesta perspectiva, a incapacidade (deficiência), é caracterizada como resultado de uma relação complexa entre o estado ou condições de saúde do indivíduo e fatores relacionados a suas vivências cotidianas (PICCOLO; MENDES, 2013).

A ausência da escola impacta drasticamente no cotidiano de estudantes que têm apenas a escola como atividade social. Muitos apresentam mudanças comportamentais em razão do cancelamento das atividades escolares, consultas médicas e atividades terapêuticas. O confinamento social prolongado tem afetado de forma significativa, não só dos estudantes com deficiências, mas de seus familiares e/ou cuidadores.

A escola e ao AEE cabe neste momento, mesmo com toda a dinâmica impeditiva que se consolida, buscar formas de manter o diálogo permanente com os órgãos gestores, além do vínculo com familiares e/ou cuidadores. Hoje o planejamento educacional especializado (PEI) torna-se ainda mais importante, pois, precisamos compreender, na complexidade de todo este processo, as principais necessidades específicas destes alunos.

Desse modo, os estudos da área da educação especial que destacam práticas diversificadas e currículos mais flexíveis, assim como a ampliação do entendimento sobre o conceito tradicional de aprendizagem, são ainda mais necessários. Mais do que nunca o currículo deve ser flexível o bastante para permitir que o professor busque soluções para suprir os impedimentos de cada aluno, principalmente no contexto de interrupção das aulas presenciais. O estudo de Pletsch et al (2017) denominado a diferenciação curricular e o desenho universal na aprendizagem como princípios para a inclusão escolar, nos oferece contribuições importantes e nos ajuda a repensar o currículo para os estudantes com deficiência num período de tantos desafios.

O referido artigo, apresenta o conceito de diferenciação curricular, como uma ferramenta que possibilita modificações e estratégias organizadas pelos professores, com o objetivo de atender a demandas específicas dos alunos no processo de aprendizagem. Porém, estas diferenciações não estão associadas a limitação, “anulação ou empobrecimento dos 
conteúdos ou objetivos a serem propostos ao aluno; mas sim à revisão de estratégias e de recursos tecnológicos usados para que o aluno com deficiência ou outras especificidades no desenvolvimento possa participar das propostas educacionais (PLETSCH ET AL, 2017, P. 271)".

[...] não se trata de elaborar um outro currículo e sim de trabalhar com o que for adotado, fazendo nele os ajustes necessários (flexibilização nos objetivos, conteúdos, metodologia de ensino, temporalidade, e nas práticas de avaliação da aprendizagem) de modo a oferecer a todos a verdadeira igualdade de oportunidades para construir conhecimentos (CARVALHO, 2008, p. 105).

Aliado ao conceito de diferenciação curricular, os autores apresentam também o conceito de desenho universal na aprendizagem (DUA), concepção que tem sido bastante difundida e importante no processo de escolarização da pessoa com deficiência. O desenho universal, definido na Convenção sobre os Direitos da Pessoa com Deficiência (BRASIL, 2009), surge como uma "concepção de produtos, ambientes, programas e serviços a serem usados, na maior medida possível, por todas as pessoas, sem necessidade de adaptação ou projeto específico".

$\mathrm{Na}$ perspectiva do desenho universal na aprendizagem, o currículo não se adapta a necessidade específica do aluno, mas apresenta diversas formas para atender a todos com o objetivo de apresentar informações e conteúdos de formas diferentes; diferenciar as formas que os alunos podem expressar o que eles sabem; estimular o interesse e a motivação para a aprendizagem (CAST, 2014 APUD SILVA ET AL, 2017, P.272 ).

Nota-se que a importância da discussão sobre a diferenciação curricular e seu entrelaçamento com o conceito de desenho universal favorece a elaboração de um conjunto de estratégias que contempla a participação de todos nos processos educativos. Em outros termos, a proposta do "desenho universal na aprendizagem sugere o acesso e a garantia da aprendizagem a todos os alunos presentes no contexto escolar, a partir do oferecimento de múltiplas e variadas formas de organizar e disponibilizar os conhecimentos científicos" (PLETSCH, 2017, p. 274).

Em um momento em que muitos alunos enfrentam dificuldades de acesso aos materiais pedagógicos por diversos motivos, é fundamental que debates neste sentido sejam encaminhados. Compreendendo os recursos tecnológicos como mais um aliado, não como mais um impeditivo, estratégias baseadas na diferenciação curricular amparadas pela concepção do DUA, em muito pode nos ajudar nessa nova realidade. A familiaridade e facilidade, por exemplo, que muitos estudantes e seus familiares apresentam com as redes 
sociais, assim como com aplicativos de comunicação são recursos que ampliam as estratégias para a democratização da educação neste período. Os vídeos, as "chamadas de vídeo", os grupos de comunicação entre outros recursos, tem sido ferramentas fundamentais na manutenção deste vínculo com a escola.

Contudo, para que estas práticas sejam efetivadas é urgente iniciativas que promovam políticas públicas comprometidas com uma educação pública de qualidade, uma vez o acesso a internet e a viabilização de materiais tecnológicos são essenciais para que isso aconteça. Quando a ausência destas ferramentas acentua ainda mais a diferença de classes, são os estudantes da escola pública que sentem os maiores impactos. "É essa reverberação que deixa explícita as carências da classe trabalhadora brasileira, mostrando objetivamente quais as dificuldades que alunos, pais e professores enfrentam neste momento" (FILHO; ANTUNES; COUTO, 2020, p. 28).

Também não podemos deixar de considerar que a saída por atividades educacionais online impõe uma expectativa exagerada sobre a capacidade das famílias, que precisam sobreviver ao vírus e arquitetar uma escola domiciliar (FILHO, 2020). Além disso, muitas não têm como acompanhar a educação de seus filhos em casa por motivos que vão desde a falta de acesso a computadores e internet, até a necessidade de trabalhar e/ou encontrar um sustento para a família.

Outra questão importante é que devemos compreender que o ERE não se trata apenas da existência ou não do acesso tecnológico, mas também envolve a complexidade representada por docentes confinados que possuem famílias e que também se encontram em condições de fragilidade em suas atividades (ARRUDA, 2020). Filho (2020) destaca que a urgência em se fazer funcionar a escola e de manter a intervenção pedagógica orientada por conteúdos e instrumentos de memorização e controle, que tem prevalecido tanto nas ações dos gestores da educação pública, quanto das empresas educacionais, tem tornado o trabalho dos professores ainda mais complexo e exaustivo.

Também, a mobilização docente para alcançar o que é requisitado pelos órgãos de gestão pedagógica acontece sob muito improviso e tensão. A transmutação do planejamento original para atividades remotas atende a um imediatismo que parece desconsiderar a crise sanitária de fato (FILHO, 2020). Mais uma vez pesam o "messianismo romântico" da atividade do professor e a negação de sua personalidade, que mesmo confinado com seus filhos e idosos, precisa ter criatividade e responsabilidade suficiente, para "ensinar" os alunos e seus familiares. 


\section{Considerações finais}

A pandemia contemporânea da Covid-19 expõe a necessidade de se desenvolver, políticas públicas de educação, que busquem ações voltadas para a preservação da dignidade, identidade cultural, do respeito à diferença e inclusão dos alunos que neste momento estão privados do direito a educação. Neste cenário, todos os envolvidos no processo educacional devem unir forças no sentido de pensar e de refletir estratégias adaptáveis a cada realidade, para que os impactos dessa crise sejam pelo menos atenuados (OLIVEIRA; SOUZA, 2020).

Atualmente, professores e estudantes de todo o país vivem o desafio de práticas pedagógicas desconhecidas e precisam se adequar a um novo modo de ensino que não contempla as condições de aprendizagens específicas de muitos estudantes. Em razão disso, possibilitar materiais e recursos diversificados, aliados a propostas curriculares mais flexíveis, pode nos ajudar a pensar recursos pedagógicos menos engessadas não só para os estudantes com deficiência, mas para todos os alunos envolvidos neste processo.

Nesta direção, os conceitos de diferenciação curricular e DUA apresentados neste artigo, em muito podem contribuir para que se pensem novas práticas, não excludentes, não só para os estudantes com deficiência, mas para todos que se encontram neste momento, deslocados dos processos de ensino. Entendemos que o período é bastante conturbado para os sistemas de ensino em todo mundo, ainda mais no caso brasileiro onde as desigualdades educacionais, que já são parte sistema, estão ainda mais agudizadas. Por isso, mais do que nunca neste momento é preciso sobretudo ter a calma necessária tendo em mente que o ineditismo leva a ações que precisam envolver toda a complexidade da qual faz parte (ARRUDA, 2020).

\section{Referências}

ARRUDA, E.P. Educação remota emergencial: elementos para políticas públicas na educação brasileira em tempos de Covid-19. Teresina. Em Rede, v. 7, n. 1, p. 257-275, maio, 2020.

BARRETO, A. C; ROCHA, D.S. Covid 19 e Educação: Resistências, Desafios e (Im)Possibilidades. Revista Encantar - Educação, Cultura e Sociedade - Bom Jesus da Lapa, v. 2, p. 01-11, jan./dez. 2020.

BERNARDES, J.A; ARRUZZO, R.C; MONTEIRO, D.M.L.V. Geografia e covid-19: neoliberalismo, vulnerabilidades e luta pela vida. Rev. Tamoios, São Gonçalo (RJ), ano 16, n. 1, Especial COVID-19. pág. 188-205, maio 2020. 
BRASIL (2020). Portaria No 343, de 17 de março de 2020. Dispõe sobre a substituição das aulas presenciais por aulas em meios digitais enquanto durar a situação de pandemia do Novo Coronavírus - COVID-19. Disponível em: http://www.in.gov.br/en/web/dou//portaria-n-343de-17-de-marco-de-2020-248564376. Acesso em: 02 abr. 2020

. Medida Provisória $N^{\circ} 934$, de $1^{\circ}$ de abril de 2020a. Estabelece normas excepcionais sobre o ano letivo da educação básica e do ensino superior decorrentes das BRASIL. Dados do INEP. Disponível em:

<www.inep.gov.br/basica/censo/Escolar/Sinopse/sinopse.asp>. Acesso em: 05 mar. 2020.

. CNE aprova diretrizes para escolas durante a pandemia, 2020 b. Disponível

em:

http://portal.mec.gov.br/index.php?option=com_content\&view=article\&id=89051\%3Acneapr ova-diretrizes-para-escolas-durante-a-

pandemia\&catid=12\&fbclid=IwAR0Im9WfdSFgf_TRg3v4Wd5IapGjuqKacjdbPBny6rWGbi x2XagiD8IEC4. Acesso em: 02 maio 2020.

. Dados do INEP. Disponível em:

<www.inep.gov.br/basica/censo/Escolar/Sinopse/sinopse.asp>. Acesso em: 05 mar. 2020.

. Ministério da Saúde. Covid-19 no Brasil. Dados atualizados. Disponível em: http://susanalitico.saude.gov.br/\#/dashboard/> Acesso em : 22 jun. 2020.

. Lei Brasileira de Inclusão, 2015. Disponível em:

http://www.planalto.gov.br/ccivil_03/_ato2015-2018/2015/lei/113146.htm. Acesso em: 24 fev. 2020. Brasília, 2008.

Política Nacional de Educação Especial na Perspectiva da Educação Inclusiva.

CARVALHO, R. E. Escola Inclusiva: a reorganização do trabalho pedagógico. Porto Alegre: Mediação, 2008.

CASTAMAN, AS; SZATKOSKI, E. Distance education in the context of professional and technological education: considerations in pandemic times. Research, Society and Development, 9(7): 1-27, 2020.

COUTO, E.S; COUTO, E.S; CRUZ, I.M.P. \#Fiqueemcasa: Educação na pandemia da Covid19. Interfaces Cientificas • Aracaju • V.8 • N.3・p. 200 - 217 • $2020 \bullet$ Fluxo Contínuo.

DINIZ, N. Reestruturação do trabalho docente e desigualdades educacionais em tempos de crise sanitária, econômica e civilizatória. Rev. Tamoios, São Gonçalo (RJ), ano 16, n. 1, Especial COVID-19. pág. 138-144, maio 2020.

FILHO, A.L.F; ANTUNES, C.F; COUTO, M.A.C. Alguns apontamentos para uma crítica da educação a distância $(\mathrm{EaD})$ na educação brasileira em tempos de pandemia. Rev. Tamoios, São Gonçalo (RJ), ano 16, n. 1, Especial COVID-19. pág. 16-31, maio 2020.

FILHO, M.M.S. Educação geográfica, docência e o contexto da pandemia COVID-19. Rev. Tamoios, São Gonçalo (RJ), ano 16, n. 1, Especial COVID-19. pág. 3-15, maio 2020. 
MOREL, A.P.M. Da educação sanitária à educação popular em saúde: reflexões sobre a pandemia do coronavírus. Revista Estudos Libertários (REL), UFRJ, Vol. 2. n ${ }^{\circ} 3$; Ed. Especial $\mathrm{n}^{\mathrm{0}} 1$. Jan/Jul 2020.

OLIVEIRA, H.V; SOUZA, S.S. do conteúdo programático ao sistema de avaliação: reflexões educacionais em tempos de pandemia (covid-19). Boletim de Conjuntura (Boca) Ano II, Vol. 2, n. 5, Boa Vista, 2020.

PICCOLO, G.M; MENDES, E.G. Contribuições a um Pensar Sociológico, p. 459-475, abr.ju. 2013. Disponível em http://www.cedes.unicamp.br

PLETSCH, M. D.; SOUZA, F. F.; ORLEANS, L. F. A diferenciação curricular e o desenho universal na aprendizagem como princípios para a inclusão escolar. Educação e Cultura Contemporânea, v. 14, p. 264-281, 2017.

PLETSCH, M. D. Desenho Universal para a aprendizagem: implementação e avaliação do protocolo do livro digital acessível. Projeto de pesquisa, Rio de Janeiro, 2017.

PLETSCH, M. D. Desafios Curriculares para a inclusão na Educação Básica. Palestra ministrada no III Seminário Internacional Aulas Conectadas: Desafios Curriculares para a inclusão na Educação Básica. Udesc/Florianópolis, agosto de 2016.

PLETSCH, M. D. Repensando a inclusão escolar: diretrizes políticas, práticas curriculares e deficiência intelectual. $2^{\circ}$ Edição revista e ampliada. Rio de Janeiro: Nau, 2014.

SILVA, G. F.; PLETSCH, M. D.; SARDAGNA, H. V; BEZERRA, A. C. S. . Educação Especial e diversidades: emergências atuais. Revista de Educação, Ciência e Cultura, v. 25, p. $7-14,2020$.

SUBNOTIFICAÇÃO: 4 indicadores de que há mais casos de covid-19 no Brasil do que o governo divulga. G1, 29/04/2020. Disponível em:

$<$ https://g1.globo.com/bemestar/coronavirus/ noticia/2020/04/29/subnotificacao-4indicadores-de-que-ha-mais-casos-de-covid-19-no-brasil-doque-o-governo-divulga.ghtml $>$ Acesso em: 3 maio 2020.

TIC DOMICÍLIOS. Pesquisa sobre o uso das tecnologias de informação e comunicação nos domicílios brasileiros. Comité gestor da internet no Brasil. São Paulo, 2019. Disponível em: $<$ https://www.cetic.br/media/docs/publicacoes/2/12225320191028 tic_dom_2018_livro_ eletronico.pdf $>$ Acesso em: 4 maio 2020.

UNESCO. Relatório de monitoramento global da educação - resumo, 2020: Inclusão e educação: todos, sem exceção, 2020. Disponível em: https://unesdoc.unesco.org/ark:/48223/pf0000373721_por. Acesso em: 22 jun. 2020.

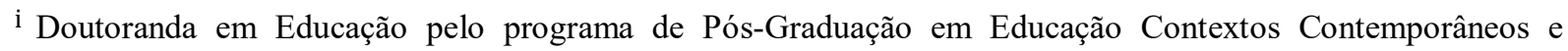
Demandas Populares da UFRRJ. Professora da Secretaria Municipal de Educação do Rio de Janeiro e Técnica em Assuntos Educacionais na Universidade Federal Rural do Rio de Janeiro. E-mail:tamafranc@yahoo.com.br. Rio de Janeiro. Brasil. ORCID: 0000-0032679-8770
} 
ii Dados disponíveis no projeto Pesquisas e ações intersetoriais entre educação e saúde na promoção da escolarização e do desenvolvimento de crianças com síndrome congênita do zika vírus na Baixada Fluminense (2019). Pesquisas e ações intersetoriais entre educação e saúde na promoção da escolarização e do desenvolvimento de crianças com síndrome congênita do zika vírus na Baixada Fluminense. Este projeto multidisciplinar articula pesquisadores de diferentes instituições (UFRRJ, UERJ, PUC-Rio e FIOCRUZ / Ensp e Instituto Fernandes Figueira) para desenvolver estudos e ações intersetoriais entre educação, saúde e assistência social na promoção da escolarização e do desenvolvimento de crianças com a síndrome congênita do zika vírus (SCZV) na Baixada Fluminense. 